\title{
Amazon nanotechnology network applied to drugs (ranaf)
}

Volume 2 Issue 2 - 2015

\section{Commentary}

Nanotechnology involves a multidisciplinary approach, gathering different areas of knowledge, such as chemistry, physics, biology, pharmacy and engineering. Despite the fact that it is associated to very small structures, nanotechnology brings significant benefits, which in the past were restricted to science fiction. One of major advantages of nanotechnology is associated to increasing surface area of nanoscale materials, making then much more reactive. These materials are not necessarily in a nanosize, but must have in their constitution nanometric structures that generate special properties and applications. For this reason, nanotechnology is recognized nowadays as one of most promising field worldwide. Pharmaceutical nanotechnology began around the $70 \mathrm{~s}$ with the introduction of liposomes as drug delivering systems. In the $80 \mathrm{~s}$, new nanoformulations, such as polymeric nanoparticles were described as innovative systems for lipophilic drugs.

Growing interest has been observed in the last years for nanostructures applied to biomedical area, especially regarding controlled release of drugs. Progressive release of the drug, transport to specific tissues, increase therapeutic index, reduce side effects, constant plasmatic levels, increased absorption and bioavailability can be considered special advantages of nanoformulations. Several types of nanoformulations have been developed, including a main group which can be classified as nanodispersions. Systems formed by two immiscible liquids and small droplets in a nanosize range, often stabilized by one or more surfactants, are called nanoemulsions. Bluish reflect associated to Tyndall effect can be observed when they are formed and several methods have been used to generate nanoemulsions, such as spontaneous emulsification, low or high energy methods. Considering the intrinsic nature of the drug, if solid insoluble substances are used, it may be usefull to prepared nanocrystals (nanosuspensions). More complex structures can be achieved by using polymeric coating, affording obtainment of nanoparticles. Polymer choice, on this specific case, is a critical point, considering that this component may modulate controlled release of substances. In all cases, utilization of economic viable methods is encouraged, which also must be reproducible and able to encapsulate the drug. Scales up have been successfully performed and nowadays, nanoformulations can be used as novel therapeutic agents by consumers.

On this context, "Rede Amazônica de Nanotecnologia Aplicada a Fármacos (RANAF)" (Amazon Nanotechnology Network Applied to Drugs) was created and started with approval of the project entitled

\author{
Caio Pinho Fernandes,' Jose Carlos Tavares \\ Carvalho' \\ 'Laboratorio de Nanobiotecnologia Fitofarmaceutica, \\ Universidade Federal do Amapa, Brazil \\ ${ }^{2}$ Laboratorio de Pesquisa em Farmacos, Universidade Federal do \\ Amapa, Brazil
}

Correspondence: Jose Carlos Tavares Carvalho, Laboratorio de Pesquisa em Farmacos, Departamento de Ciencias Biologias e da Saude, Curso de Farmacia, Universidade Federal do Amapa, Rod. Juscelino Kubitschek, km 02, CEP 68902-280, Macapa, Amapa, Brazil Email farmacos@unifap.br

Received: October 04, 2015 | Published: April 15, 2015
"Nanoencapsulation of anti-inflammatory drugs from synthetic and natural origin in polymeric matrix for controlled release", with had finantial support from Brazilian Research Concil (CNPq, register number 564745/2010-3). RANAF has been performing a main whole to consolidate nanotechnology research through Amazon institutions, being also supported by important groups from other countries, such as Cuba and France (French Guyanne). Great Amazon biodiversity, which is outstanding in Amapá State (Brazil), can be sustainably used in order to achieve innovative natural product based nanoformulations. This is a main aim of RANAF studies, being applicable not only for pharmaceuticals, but also for food, cosmetics, pesticides and other products. Recently, the Laboratory of Phytopharmaceutical Nanobiotechnology was created to involve all development steps, being decisive together with Drug Research Laboratory, to carry RANAF research for different applications, including nanonutraceuticals and nanomedicines for anti-inflammatory, antidepressant, ansiolítica and erectile dysfunction treatment, among others.

\section{Acknowledgments}

None.

\section{Conflicts of interest}

None. 